\title{
As relações de sentido em anúncios publicitários: teoria da argumentação na língua e a construção de blocos semânticos
}

\author{
Keila de Quadros Schermack \\ Doutoranda pelo PPG em Letras da Universidade de Passo Fundo, Brasil \\ http://orcid.org/0000-0001-6514-613X
}

\section{Ernani Cesar de Freitas}

Docente do PPG em Letras da Universidade de Passo Fundo e do PPG em Processos e Manifestações Culturais da Universidade Feevale, Brasil http://orcid.org/0000-0002-8920-9446

Resumo: A temática deste estudo consiste em aplicar conceitos da Teoria da Argumentação na Língua (TAL), de Ducrot (1990) e colaboradores, mais especificamente no que se refere à fase atual da teoria: a Teoria dos Blocos Semânticos (TBS). O objetivo desta pesquisa é analisar a construção do sentido dos enunciados pela argumentação que se estabelece, exclusivamente por meio da língua, no discurso do anúncio publicitário. O marco teórico aborda as noções sobre Semântica Argumentativa de Ducrot (1990, 2005a) e Carel (2002, 2005a), com base nos conceitos teóricos: encadeamentos argumentativos, argumentação externa e argumentação interna. A pesquisa é exploratória, bibliográfica e qualitativa. $\mathrm{O}$ corpus é composto de dois anúncios publicitários da Coca-Cola (The Coca-Cola Company). Constamos que a argumentação utilizada pelo locutor no discurso está pautada nos aspectos normativo e transgressivo, revelando que a língua em uso, por si só, estabelece as relações de sentido na construção argumentativa dos textos.

Palavras-chave: Teoria da Argumentação na Língua. Teoria dos Blocos Semânticos. Anúncios publicitários. Sentido.

Abstract: The theme of this study is to apply concepts from the Theory of Argumentation in Language (TAL), by Ducrot (1990) and collaborators, more specifically with regard to the current phase of the theory: the Theory of Semantic Blocks (TBS). The objective of this research is to analyze the construction of the meaning of the utterances by the argumentation that is established, exclusively through the language, in the discourse of the advertisement. The theoretical framework addresses the notions about Argumentative Semantics by Ducrot (1990, 2005a) and Carel (2002, 2005a), based on the theoretical concepts: argumentative chains, external argumentation and internal argumentation. The research is exploratory, bibliographic and qualitative. The corpus consists of two advertisements for Coca-Cola (The Coca-Cola Company). We note that the argument used by the speaker in the discourse is based on the normative and transgressive aspects, revealing that the language in use, by itself, establishes the relations of meaning in the argumentative construction of the texts.

Keywords: Theory of Argumentation in Language. Semantic Blocks Theory. Advertising. Sense. 


\section{Introdução}

O tema deste artigo tem como foco a aplicação de alguns conceitos da Semântica Argumentativa, perspectiva teórica que estuda o sentido construído pelo linguístico sem fazer intervir o extralinguístico. A delimitação do trabalho consiste em um exercício de aplicação teórico-prática em anúncios publicitários, com base na Teoria dos Blocos Semânticos (TBS), vinculada à Teoria da Argumentação na Língua (TAL), de Oswald Ducrot (1990) e colaboradores.

Argumentar é uma forma de aproximar a língua da expressão plena das ideias. Uma das funções fundamentais da linguagem é a intersubjetividade, o lugar onde o locutor encontra seu interlocutor. Então, quando um locutor realiza escolhas na língua e produz discurso, expressa seus pensamentos por meio de enunciados, levando seu alocutário a dar-lhe uma resposta. Em vista disso, argumentar é levar o interlocutor a uma determinada continuação. Nesse sentido, salientamos a importância de um estudo sob o enfoque teórico metodológico da Semântica Argumentativa, especialmente da TBS, uma vez que essa teoria contribui para pensar a língua em uso, enquanto ela mesma, sem influências da realidade extralinguística.

A questão norteadora deste estudo parte do fato de que os conceitos teóricos da TAL, mais especificamente de sua fase atual, a TBS, podem ser aplicados para descrever o sentido produzido pelos enunciados no discurso dos anúncios publicitários, uma vez que contribuem para a leitura do texto como um conjunto de encadeamentos argumentativos, ligados sob os aspectos normativo (donc = portanto/então) e transgressivo (pourtant = no entanto/mesmo assim).

O objetivo desta pesquisa é analisar a construção do sentido dos enunciados pela argumentação que se estabelece, exclusivamente por meio da língua, no discurso dos anúncios publicitários. A TBS aplicada ao anúncio publicitário possibilita perceber o sentido depreendido dos encadeamentos das palavras e dos enunciados, visto que a significação dos blocos semânticos não resulta da soma dos sentidos das palavras que os compõem, tomadas isoladamente, mas da interdependência semântica existente entre elas.

No que diz respeito à fundamentação teórica, conferimos especial destaque a contribuições referentes à Semântica Argumentativa de Oswald Ducrot (1990, 2005a) e Marion Carel (2002, 2005a), com base nos conceitos teóricos que compõem a TBS a argumentação externa e a argumentação interna aos enunciados, os encadeamentos argumentativos e os blocos semânticos. 
Foi sob esse enfoque que elaboramos o percurso metodológico: a pesquisa é exploratória, bibliográfica e qualitativa. O corpus escolhido corresponde a dois anúncios publicitários da Coca-Cola (The Coca-Cola Company), corporação multinacional estadunidense, fabricante e comerciante de bebidas. Selecionamos um anúncio do ano de 2014 e outro de 2016, pelo fato de que a construção argumentativa dos enunciados nesses textos corresponde ao objetivo da pesquisa.

Estruturalmente, o texto está assim organizado: na primeira seção, detalhamos breves conceitos teóricos acerca da TAL. Na segunda seção, abordamos, especificamente, a TBS. Prosseguimos com os procedimentos metodológicos, seguidos da seção de análise do corpus e de alguns resultados. Por fim, constam as considerações finais e as referências.

\section{Teoria da argumentação na língua: da fase standard à tbs}

A Teoria da Argumentação na Língua ( $T A L)$ se inscreve na área de estudos da Semântica Argumentativa, criada em 1983 por Oswald Ducrot, e continuada atualmente por Ducrot e Marion Carel, na École des Hautes Études en Sciences, centro de pesquisa de Paris, na França. Essa perspectiva teórica se centra na hipótese de que a argumentação está inscrita na língua e não depende de um contexto externo.

Nesta seção, apresentamos uma breve contextualização sobre as fases da teoria defendida por Ducrot $(1987,1990)$ e, posteriormente, reelaborada por Carel (2005a) e Ducrot (2002, 2005a). Em seguida, esclarecemos alguns conceitos teóricos que compõem a TAL.

O objeto de estudo da TAL é o sentido linguístico que se produz no discurso, no emprego da língua. Dessa forma, o enunciado ${ }^{1}$ é tomado como um produto da enunciação constituído na relação interna entre segmentos e relações externas com outros enunciados do texto.

A TAL fornece subsídios para a compreensão do funcionamento da linguagem em uso, uma vez que é uma teoria enunciativa. Ducrot (1990) define a enunciação como o surgimento do enunciado, tornando-se este o objeto de suas análises, sem, contudo, se desvincular, em nenhum momento, de sua perspectiva enunciativa (BARBISAN, 2006). O foco de análise da teoria de Ducrot (1990) é a argumentação, ou seja, as marcas que o locutor, responsável pelo enunciado, coloca em seu discurso.

\footnotetext{
${ }^{1}$ A noção de enunciado apresenta alterações nas diferentes fases do estudo semântico da língua de Ducrot (FLORES
} et al., 2009). 
Essas marcas se apresentam tanto de forma explícita, do ponto de vista da relação entre locutor e interlocutor, quanto entre o locutor e outros sujeitos, os enunciadores, que dialogam com o locutor em diferentes níveis de implicitação, postulando a não unicidade de sujeitos do enunciado. Então, as relações de significação se estabelecem não apenas entre palavras ou frases, mas igualmente entre discursos.

Ducrot (1990) concebe a argumentação em uma acepção que a distingue completamente da concepção chamada "tradicional ingênua da argumentação". Segundo o linguista, a ideia de que o argumento toma seu valor independentemente da conclusão é inadmissível, porque as palavras não têm sentido completo antes das conclusões que tiramos delas. Por isso, Ducrot (1990) considera insuficiente essa concepção tradicional de argumentação, já que (A) não possui um valor de verdade em si mesmo sem que a conclusão seja conhecida pelo locutor. Por essa razão, "o poder argumentativo de um enunciado não se determina somente pelo fato que expressa esse enunciado, mas também por sua forma linguística" (DUCROT, 1990, p. 79).

A TAL experimentou diferentes fases e formas ao longo de seu desenvolvimento. A primeira fase da teoria, conhecida como fase standard, centra-se na ideia de que uma argumentação é necessariamente uma concatenação de dois segmentos do discurso: o argumento e a conclusão (FLORES et al., 2009). As palavras são portadoras de argumentações, sendo que o valor argumentativo ${ }^{2}$ de um enunciado, o sentido, definese como o conjunto das conclusões às quais se pode chegar a partir dele e depende da continuidade discursiva de enunciados.

Na fase standard, Ducrot (1990) determina algumas noções semânticas indispensáveis para entender a Teoria da Argumentação. Primeiramente, diferencia os conceitos de frase e enunciado, após, distingue os conceitos de sentido e significação. Nas palavras de Ducrot (1990, p. 65), “o enunciado é a realidade empírica, observável”. O signo é a frase, isto é, estrutura abstrata, criada pelo linguista, e seu significado é constituído pelas possibilidades de relação semântica que ela apresenta com outras frases. Então, não se pode ler nem ouvir frases, somente enunciados.

Ducrot (1990) estabelece uma diferença de natureza entre o sentido e a significação e propõe uma concepção aberta, instrucional, da significação. Chama sentido ao valor semântico do enunciado e significação ao valor semântico da frase, que está constituído por diretrizes, instruções para a interpretação do enunciado.

\footnotetext{
2 Flores et al (2009) definem o valor argumentativo como conjunto de possibilidades ou impossibilidades de continuação discursiva que o emprego de uma palavra determina, decorrente da unificação dos aspectos subjetivo e intersubjetivo da linguagem.
} 
A argumentação é o resultado da relação entre o segmento enunciado argumentativo (A) e o enunciado conclusão (C). No exemplo dos enunciados "Faz sol, vamos à praia" e "Faz sol, não vamos à praia", o valor argumentativo da expressão "faz sol" varia de acordo com as conclusões que se tira dela. Segundo Freitas (2007, p. 122), "existem expressões na língua que têm por si mesmas um valor argumentativo, o que significa que essas expressões impõem, determinam por si mesmas, o valor argumentativo dos enunciados em que aparecem". No primeiro caso do exemplo, o sol é favorável para ir à praia, já no segundo, desfavorável.

A ideia segundo a qual cada expressão argumentativa deve levar a conclusões diversas passa a ser discutida na segunda fase da TAL, com a Teoria dos Topoi ${ }^{3}$ Argumentativos. Conforme Barbisan e Teixeira (2002, p. 171, grifo dos autores), "o topos é um princípio argumentativo, um lugar-comum argumentativo, que serve de intermediário entre o argumento e a conclusão". A reformulação da forma standard dá lugar à forma standard ampliada, que acrescenta à TAL as noções de topos e de polifonia.

Ducrot (1990) busca rechaçar a chamada concepção veritativa da significação, a qual estabelece que as palavras têm como função principal dar uma representação da realidade e as frases da língua, um julgamento em termos de verdade e de falsidade. Na segunda fase da teoria, o linguista discute a possibilidade de duas frases, que comportam o mesmo operador argumentativo, permitirem conclusões diferentes sem se distinguirem no que diz respeito aos fatos enunciados por elas (FUMAGALLI; FREITAS, 2017).

O potencial argumentativo se relaciona ao conjunto de topoi (crenças) que pode ser evocado por uma entidade determinada. Um enunciado como "Faz sol, vamos sair", de acordo com Ducrot (1990), só teria real significação se fosse verificada a realidade da comunidade responsável pela produção do enunciado. Em alguns estados do Brasil, como, por exemplo, no Piauí, as pessoas evitam sair no sol, porque as temperaturas chegam em torno de $39^{\circ} \mathrm{C}$ a $40^{\circ} \mathrm{C}$. Assim, na realidade dessa comunidade, "fazer sol” não é um bom indício para sair de casa. Nesse caso, chegariam à conclusão: "Faz sol, vamos ficar em casa".

Em "Esboço de uma teoria polifônica da enunciação", Ducrot (1987) ressalta a necessidade de se reconhecer e identificar as várias vozes que permeiam um discurso. Ao contestar o entendimento folclórico e ingênuo de as pesquisas linguísticas insistirem na unicidade do sujeito falante, mostra que o sentido do enunciado

\footnotetext{
${ }^{3}$ A Teoria dos Topoi Argumentativos tem como tese central a ideia de que a relação argumento conclusão, que constitui o sentido dos enunciados de uma dada língua, é garantida (e/ou medida) por um lugar comum argumentativo, o topos (FLORES et al., 2009).
} 
apresenta um certo número de pontos de vista, e destes se depreende o sentido do dizer. Ao fazer intervir o conceito de polifonia na sua TAL, fundamentado na noção de topos, Ducrot (1987) concebe a argumentação não mais em termos de enunciados, e, sim, em relação aos enunciadores. Sob essa ótica, a enunciação não está ligada ao ato, mas ao fato de que um enunciado aparece.

Com a evolução da TAL, Carel e Ducrot (2005a) perceberam que a noção de topos aliada à teoria estava desvinculada do princípio estruturalista de estudar a língua por ela mesma, sem referências ao meio extralinguístico. Nesse sentido, Ducrot (2005a) refletiu que, ao introduzir os topoi, embasava as relações argumentativas em princípios que não são da ordem linguística. Em outras palavras, apoiava-se a argumentação em noções independentes da língua, renunciando ao princípio saussuriano segundo o qual a língua é estudada por ela mesma.

Diante disso, Marion Carel percebeu que a Teoria dos Topoi contrariava a TAL, uma vez que recorria a elementos pertencentes ao mundo exterior, enquanto que $o$ princípio da TAL estaria voltado para uma argumentação de ordem unicamente linguística. Assim, o conceito de argumentação é revisto, e a noção de topos dá lugar à Teoria dos Blocos Semânticos (TBS), forma atual da teoria, que passa a ser desenvolvida por Carel e Ducrot (2005a) a partir de 1992.

A próxima seção conta com os principais conceitos teóricos da fase atual da TAL, evidenciando que a argumentação está inscrita no próprio sistema linguístico.

\section{Teoria dos blocos semânticos: a argumentação inscrita na língua}

$\mathrm{Na}$ TBS, a argumentação não mais se alicerça pela passagem do argumento, que funciona como justificativa para a conclusão. Segundo Ducrot (2005C), a ideia central da teoria é que o próprio sentido de uma expressão é dado pelos discursos argumentativos que podem encadear-se a partir dessa expressão. O sentido de uma entidade linguística é construído pela interdependência entre os dois segmentos dos encadeamentos argumentativos.

A TBS desenvolve e aprofunda a ANL sem alterar as bases conceituais que a fundamentam. Para precisar essa herança teórico conceitual, leiam-se as seguintes palavras de Marion Carel (CAREL; GOMES, 2019, p. 260): “O que a TBS retomou da ANL é a hipótese geral segundo a qual falar consiste em construir um texto, em restringir a fala do interlocutor, em entrelaçar palavras". A TBS, assim como a ANL, antes dela, 
levanta a hipótese de que nossos discursos são organizados argumentativamente, e essa organização está prefigurada na significação das palavras.

Nessa fase, a argumentação é constitutiva do sentido de uma entidade linguística e argumentar passa a ser produzir discurso pela convocação de blocos lexicais, por meio de encadeamentos argumentativos que exprimem uma qualidade, positiva ou negativa, que, juntamente com o bloco, compõem uma regra. Segundo Ducrot (2005b, p. 29, tradução nossa4): “Para a TBS, o sentido de qualquer expressão, seja uma palavra ou uma afirmação, está constituído pelos discursos que essa expressão evoca. Chamamos esses discursos de encadeamentos argumentativos".

Um encadeamento argumentativo é constituído por uma sequência de proposições (dois segmentos), ligadas sintaticamente pela forma geral X CONECTOR Y. No entanto, Carel e Ducrot (2005a) só admitem dois tipos de conectores e dois tipos de encadeamentos argumentativos: os encadeamentos normativos DC, com conectores do tipo "portanto (donc)", e os encadeamentos transgressivos PT, com conectores do tipo "no entanto e/ou mesmo assim (pourtant)".

Na TBS, o segmento $X$ é chamado de $A$ e o segmento $Y$, de $B$, ambos podem ou não estar acompanhados de uma negação e são fundamentais para a conexão em DC ou PT que é estabelecida pelo encadeamento. O conector desempenha o papel de expressar a relação entre o primeiro e o segundo segmento. Pelo fato de serem teóricos, eles são o resultado de uma construção do linguista e representam uma classe de conjunções que expressam seja a norma linguística, seja a transgressão, por meio de portanto ou de no entanto.

Essas relações normativas e transgressivas são sentidos derivados de determinada interpretação, "pois o sentido construído pela relação não toma os segmentos numa ordem linear ou unilateral, mas surge a partir da interdependência semântica" (LEBLER, 2018, p. 25, grifo do autor). Norma e transgressão são os dois únicos tipos de relação que dizem respeito à essência da linguagem e podem ser expressos em qualquer enunciado da língua.

A interdependência entre os segmentos de um enunciado tem como resultado a construção de um conteúdo, que pode ser expresso de quatro formas. A partir de (A) e de (B), podem ser construídas diferentes relações discursivas, chamadas de "aspectos argumentativos", responsáveis por formar, posteriormente, o "quadrado argumentativo", noção destinada a formalizar a de "bloco semântico" (DUCROT, 2005b).

\footnotetext{
4 "Para la TBS, el sentido de uma expresión cualquiera, sea ella uma palabra o um enunciado, está constituido por los discursos que esa expresión evoca. A estos discursos los llamamos encadenamientos argumentativos" (CAREL; DUCROT, 2005b, p. 29).
} 
Ao seguir a ideia de normativo e transgressivo, Carel e Ducrot (2005a, p. 22-23, tradução nossa) apresentam o primeiro bloco semântico $\left(\mathrm{BS}_{1}\right)$ :

ACON B

A CON' Neg-B

Neg-A CON'B

Neg-A CON Neg-B (CAREL; DUCROT, 2005a, p. 22).

O segundo bloco semântico $\left(B_{2}\right)$ apresenta os seguintes aspectos:

A CON Neg-B

A CON'B

Neg-A CON B

Neg-A CON'Neg-B (CAREL; DUCROT, 2005a, p. 24).

Na concepção de Carel e Ducrot (2005a), A é o segmento argumento, C é o segmento conclusão, CON é a abreviação de conector e CON' (conector linha) representa um conector contrário a CON. Assim, se CON for normativo DC (portanto), CON' será transgressivo PT (no entanto). De outro modo, é possível considerar ambos os conectores inversamente: se CON designa PT, CON' vai designar DC. E a abreviação “Neg” indicará a negação.

Conforme Gomes (2020, p. 75), “os encadeamentos argumentativos - também chamados apenas de argumentações - parafraseiam o sentido de enunciados e são realizados externa e internamente pela língua". É necessário destacar que, na argumentação do encadeamento normativo ou transgressivo, a ligação ou argumentação entre os enunciados pode ser manifestada de forma tanto externa (AE) quanto interna $(\mathrm{Al})$.

A argumentação externa de uma entidade linguística deve conter aspectos nos quais ela figura como antecedente ou como consequente. De acordo com Ducrot (2002, p. 08): "Um aspecto é evocado por uma entidade de modo externo, se essa entidade constitui um segmento do aspecto". Conforme exemplo da palavra "prudente", temos tanto a AE normativa "prudente DC confiança" quanto seu converso, a AE transgressiva "prudente PT neg-confiança”. A argumentação externa de uma entidade está constituída por aspectos cujos encadeamentos contêm essa entidade. Cada aspecto em CON da (AE) está associado a um aspecto em CON' mais Neg. Por isso, a argumentação de "prudente" pode apresentar o aspecto A DC B e, também, o aspecto converso A PT neg-B.

Quando uma entidade lexical como, por exemplo, “ter pressa" é o primeiro segmento do encadeamento argumentativo, o aspecto está relacionado a ele de modo externo à direita, e são assinaladas as consequências de ter pressa: "ter pressa DC 
(donc - portanto) agir rapidamente". Se a entidade lexical "ter pressa" é o segundo segmento do encadeamento, dizemos que o aspecto relacionado a ela é externo à esquerda: "agir rapidamente DC (donc - portanto) ter pressa", em que é indicada a causa de ter pressa.

Já a argumentação interna (Al) é constituída por um certo número de aspectos que pertencem aos encadeamentos que parafraseiam uma entidade lexical. Como a argumentação interna é um encadeamento argumentativo que se constitui numa espécie de reformulação, essa entidade não é, ela própria, um segmento desse encadeamento. Por exemplo: a Al de "prudente" é "perigo DC (donc- portanto) precaução", que não contém a entidade lexical "prudente". Na perspectiva de Ducrot (2005C), a Al não está materialmente marcada no enunciado, pois é uma expressão próxima da realizada, uma paráfrase do discurso.

Segundo Ducrot (2005C), se existir em uma Al um aspecto $X \operatorname{CON} Y$, não se encontrará nessa mesma Al um aspecto que contenha o encadeamento converso $X$ CON'Neg-Y. A principal diferença entre a $A E$ e a Al reside no fato de que na $A E$ temos $D C$ e $P T$. Já, na $A l$, se tem $D C$, não se tem $P T$, e se tem $P T$, não se tem $D C$. Desse modo, uma entidade não pode admitir ao mesmo tempo em sua Al um aspecto e o aspecto converso.

Depois de deferidas e analisadas a AE e a AI de um enunciado, poderemos obter o que chamamos, na TBS, de bloco semântico, que se define como "entidade semântica, unitária e indecomponível, subjacente a encadeamentos argumentativos" (FLORES et al., 2009, p. 57). Cada bloco semântico é composto por um quadrado argumentativo que possui relações discursivas. Essas relações discursivas podem ser transpostas, recíprocas e conversas. Os blocos semânticos construídos a partir dos enunciados de um discurso permitem que sua estrutura argumentativa fique evidente, ou seja, o modo como a argumentação do discurso é produzida.

Com base na exposição feita sobre a TBS neste estudo, analisaremos dois anúncios publicitários da Coca-Cola (The Coca-Cola Company), recorrendo a alguns conceitos teóricos apresentados. Certamente, muitas considerações teóricas ainda poderiam ter sido feitas acerca da TBS, uma vez que essa fase da TAL continua sento analisada e aprimorada por seus autores, principalmente por Marion Carel. No entanto, optamos por delimitar algumas noções básicas, fundamentais para a análise do corpus selecionado.

A próxima seção traz os procedimentos metodológicos definidos para a análise da construção do sentido dos enunciados, nos encadeamentos argumentativos depreendidos dos anúncios publicitários. 


\section{Procedimentos metodológicos de análise}

Nesta seção, esclarecemos os procedimentos metodológicos adotados para a condução do estudo, que tem como base a obra Metodologia do trabalho científico, de Prodanov e Freitas (2013).

O corpus de pesquisa constitui-se de dois anúncios publicitários da Coca-Cola. O primeiro anúncio, de 2014, foi objeto de análise de uma dissertação de mestrado, intitulada $\mathrm{O}$ modo Coca-Cola de ser feliz: ideais de bem viver nas campanhas publicitárias dos anos 1960 e 2000, sob autoria de Amanda Volotão (2015). O segundo anúncio foi veiculado no site da Coca-Cola Brasil - página que retrata a história da empresa - no dia 24 de maio de 2016.

Sob o ponto de vista de seu objetivo, a pesquisa é exploratória. Do ponto de vista dos procedimentos técnicos, ou seja, da maneira pela qual obtivemos os dados necessários para compor este estudo, destacamos a pesquisa bibliográfica mediante abordagem qualitativa (PRODANOV; FREITAS, 2013). Inicialmente, partimos de um levantamento bibliográfico a respeito da Semântica Argumentativa, área de estudos na qual se inscreve a TAL, desenvolvida por Ducrot (1990, 2005a) e Carel (2005a), a fim de compreender o caminho teórico percorrido pelos linguistas até chegar ao atual momento, a TBS, fase que embasará a análise do corpus.

A fim de contribuir para o entendimento sobre como o sentido é construído nos anúncios publicitários, tendo por base a TAL, realizaremos, em um primeiro momento, a seleção (recorte) dos enunciados em diferentes segmentos. Posteriormente, esses segmentos constituirão os encadeamentos argumentativos que formarão os blocos semânticos. Esses encadeamentos serão analisados, argumentativamente, pelo uso de conectores implícitos (portanto/então - DC; no entanto/mesmo assim - PT).

Em um terceiro momento, analisaremos a construção argumentativa dos anúncios. Nessa etapa, identificaremos as argumentações externas (AE) e internas (Al) dos enunciados, que instruem o movimento da argumentação para a construção do primeiro quadrado argumentativo, correspondente ao primeiro bloco semântico (BS $)$.

Após, realizaremos a descrição semântica dos demais enunciados dos anúncios, com vistas à elaboração do segundo bloco semântico $\left(\mathrm{BS}_{2}\right)$. Os encadeamentos argumentativos que compõem os dois primeiros blocos semânticos serão articulados entre si, a fim de enfatizar o sentido construído pelo discurso. Delineamos o marco teórico com destaque para alguns conceitos teóricos de análise, conforme podemos verificar no Quadro 1: 
Quadro 1 - Marco teórico e conceitos de análise

\begin{tabular}{|l|l|}
\hline $\begin{array}{l}\text { TEORIA DA ARGUMENTAÇÃO NA LÍNGUA } \\
\text { TBS }\end{array}$ & CONCEITOS TEÓRICOS \\
\hline $\begin{array}{l}\text { Oswald Ducrot (1990, 2002, 2005a, 2005b, 2005c). } \\
\text { Marion Carel (2002, 2005a). }\end{array}$ & $\begin{array}{l}\text { - aspecto } \\
\text { - encadeamento } \\
\text { - argumentação externa } \\
\text { - argumentação interna } \\
\text { - quadrado argumentativo } \\
\text { - bloco semântico }\end{array}$ \\
\hline
\end{tabular}

Fonte: elaboração dos autores.

Como sugerem os conceitos teóricos no Quadro 1, a análise do corpus fundamenta-se nos conceitos oriundos da TAL, mais especificamente na TBS de Ducrot (1990, 2002, 2005a, 2005b, 2005c) e Carel (2002, 2005a). Com o intuito de esclarecer o percurso metodológico, elaboramos o dispositivo de análise exposto na Figura 1.

Figura 1 - Dispositivo metodológico de análise

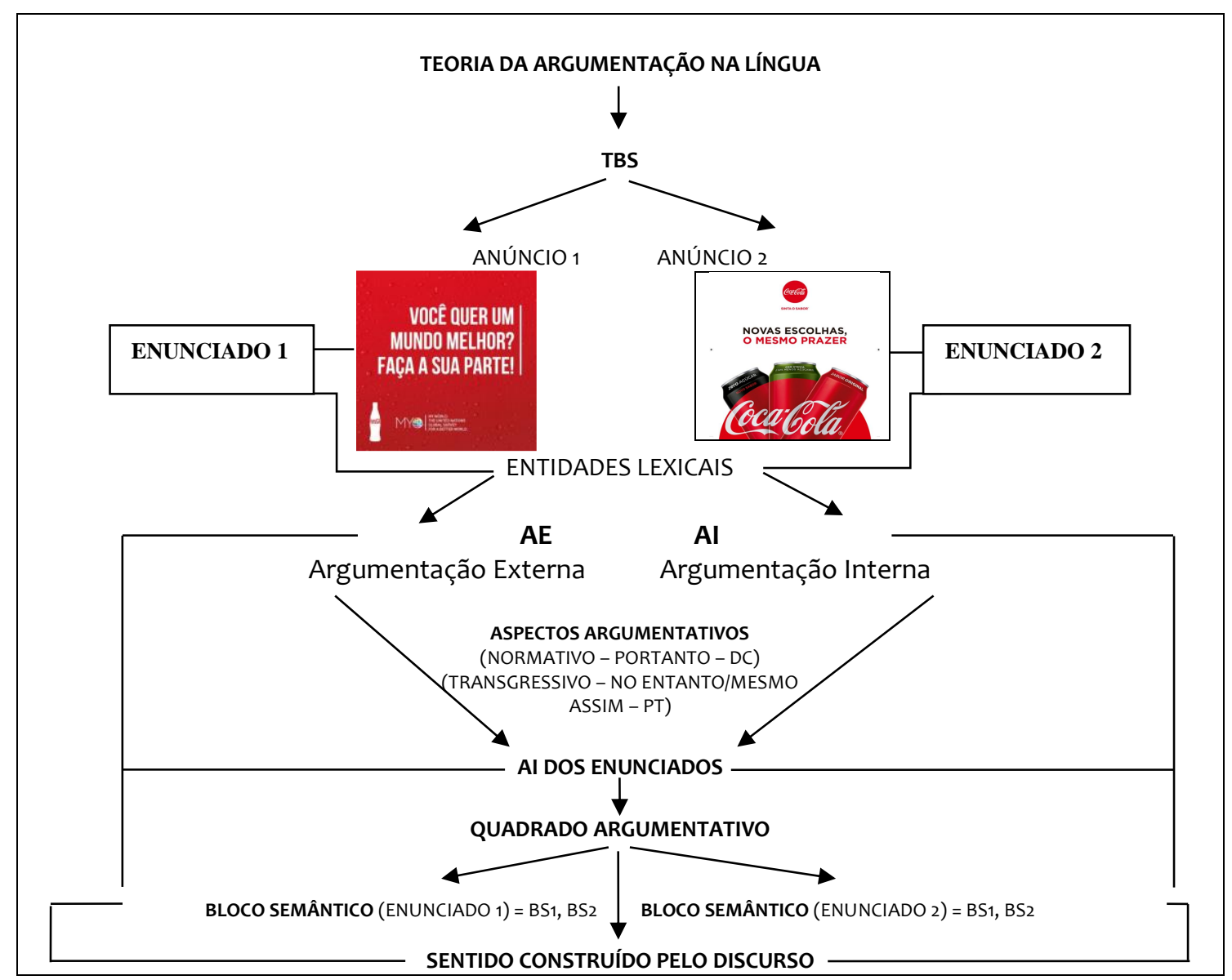

Fonte: Elaboração dos autores. 
De acordo com os procedimentos metodológicos já descritos, apresentaremos, na seção seguinte, a análise do corpus.

\section{A construção do sentido nos anúncios publicitários: análise e resultados}

Com o objetivo de analisar a construção do sentido dos enunciados pela argumentação que se estabelece exclusivamente por meio da língua no discurso dos anúncios publicitários, destacamos o corpus de pesquisa desta análise: dois anúncios da Coca-Cola, um de 2014 e outro de 2016. O primeiro anúncio faz parte da campanha publicitária cujo tema remete à busca por um "mundo melhor" ("For a better world"). O segundo anúncio pertence à campanha "Taste the feeling" ("Sinta o sabor").

É importante esclarecer que a escolha desse corpus se deve ao fato de que os anúncios publicitários exercem um papel relevante em sociedades capitalistas, pois, muitas vezes, provocam mudanças no comportamento das pessoas. O texto publicitário usa, principalmente, o sistema linguístico para difundir uma mensagem de lazer, felicidade, renovação e beleza, influenciando o interlocutor. Assim, o anúncio publicitário, pela organização e seleção lexical e por outros recursos como as imagens (texto não verbal), por exemplo, cria no consumidor a necessidade de adquirir um determinado produto.

Embora os anúncios estejam destacados em sua íntegra, contendo texto verbal e não verbal, com alguns enunciados em língua inglesa, o foco desta análise são os elementos verbais em língua portuguesa. Para iniciar a análise, é necessário lembrar que "nem toda interpretação é possível, pois as palavras da língua possuem um conteúdo semântico definido [...], a palavra utilizada fornece uma orientação argumentativa e o alocutário a percebe no enunciado" (FREITAS, 2007, p. 100-101). Dessa forma, é importante destacar o fato de que todas as palavras pertencem a universos semânticos determinados e que classificá-las é fazer suposições de argumentos.

Portanto, analisamos primeiramente o anúncio publicitário apresentado na Figura 2. 
Figura 2- Anúncio publicitário da Coca-Cola de 2014: "Por um mundo melhor"

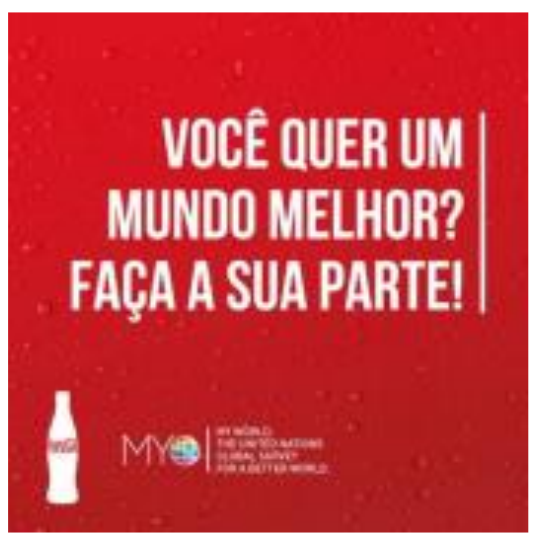

Fonte: Volotão (2015, p. 87).

Vejamos o enunciado 1: "Você quer um mundo melhor? Faça a sua parte!”.

Os encadeamentos argumentativos são qualificados como discursos constituídos por dois segmentos que, de um ponto de vista semântico, possuem uma interdependência de sentido. Essa relação de interdependência pode se apresentar de duas formas, a partir de um conector normativo DC (donc - portanto) ou transgressivo PT (pourtant - mesmo assim), porém, é preciso lembrar que "nem sempre os marcadores do normativo ou do transgressivo estarão explícitos" (GOMES, 2017, p. 93). O corpus de análise deste estudo é um exemplo desse caso, pois temos encadeamentos normativos e transgressivos em funcionamento na construção do sentido, mas eles não estão marcados explicitamente na materialidade linguística. Vale observar que o enunciado interrogativo evoca uma resposta, uma continuação, que sugere a presença (implícita) do conector normativo (DC/ donc/então - portanto).

Para analisar o sentido do enunciado e seus segmentos, é necessário explicitar o encadeamento argumentativo que eles permitem evocar. Construiremos, então, quatro aspectos argumentativos, tanto em DC (normativo) como em PT (transgressivo), como podemos observar na sequência:

A- X DC Y: Querer um mundo melhor DC fazer a sua parte

B- X PT NEG-Y: Querer um mundo melhor PT não fazer a sua parte

C- NEG-X DC NEG- Y: Não querer um mundo melhor DC não fazer a sua parte

D- NEG- X PT Y: Não querer um mundo melhor PT fazer a sua parte

Temos, assim, quatro aspectos argumentativos que são pluralidades de discursos, formando argumentações possíveis do enunciado. Segundo Carel (2002), o conector utilizado no enunciado não liga duas informações distintas, mas, antes, marca a dependência semântica entre os segmentos discursivos que ele liga. O sentido do 
enunciado só poderá ser apreendido em sua totalidade quando levarmos em consideração os dois segmentos ligados pelo conector (A CON B). A partir das quatro possibilidades discursivas apresentadas pelo enunciado, é necessário definir um desses aspectos para compor o sentido pretendido pelo locutor no discurso do anúncio publicitário. Conforme Barbisan (2013, p. 21), "quando o locutor produz discurso, está expressando seu pensamento por meio de enunciados, e levando seu alocutário a darIhe uma resposta". Em decorrência, o enunciado é definido não só nele mesmo, mas também nas possibilidades para a sua continuação.

Logo, o aspecto "Querer um mundo melhor DC fazer a sua parte" é aquele que condiz com a argumentação apresentada no enunciado. $O$ aspecto escolhido pelo enunciador apresenta uma argumentação em donc (então/portanto), ou seja, normativa. Desse modo, agora, vamos nos ater aos encadeamentos parafrásticos (DUCROT, 2005C), ou seja, a argumentação interna (AI) do enunciado: "Desejar um lugar ideal DC ser agente transformador".

Com esse novo encadeamento, resultante da paráfrase da argumentação externa, construímos quatro aspectos pertencentes ao mesmo bloco, uma vez que o "[...] próximo passo consistirá em incluir cada um dos quatro aspectos dentro da noção de quadrado argumentativo5" (DUCROT, 2005b, p. 44, tradução nossa). Recordamos que pertencer ao mesmo bloco significa que existe a mesma interdependência semântica entre A e B. É importante ressaltar que A e B, aqui, podem ser lidos como $X$ e $Y$, para evitar possíveis incongruências entre as noções de segmentos e aspectos argumentativos. Apresentamos, a seguir, o primeiro quadrado argumentativo:

E-X DC Y: Desejar um lugar ideal DC ser agente transformador

F-X PT NEG-Y: Desejar um lugar ideal PT não ser agente transformador

G- NEG-X DC NEG-Y: Não desejar um lugar ideal DC não ser agente transformador

H- NEG-X PT Y: Não desejar um lugar ideal PT ser agente transformador

O quadrado argumentativo, que forma, então, o Bloco Semântico 1 (BS1), pode ser ilustrado conforme a Figura 3:

5 "[...] próximo paso consistirá en incluir cada uno de estos cuatro aspectos dentro de la noción de cuadrado argumentativo" (DUCROT, 2005b, p. 44). 
Figura 3 - Bloco Semântico 1

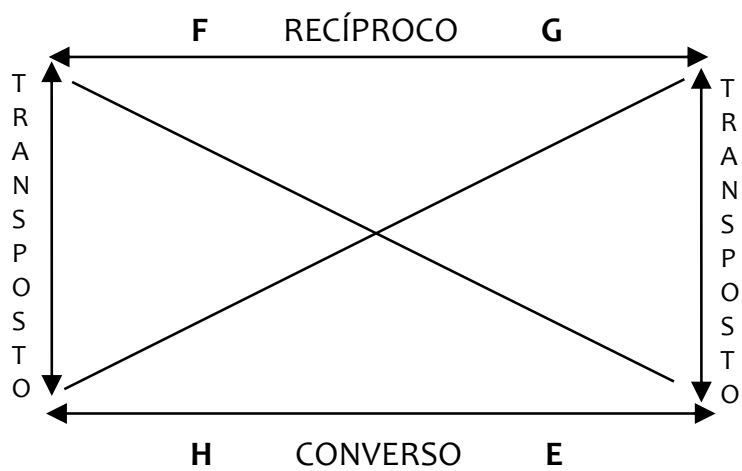

Fonte: elaboração dos autores.

A Figura 3 mostra as relações recíprocas, conversas e transpostas entre os aspectos argumentativos. Analisando os aspectos argumentativos que formam o Bloco Semântico 1, percebemos que, dentro das possibilidades semânticas evocadas pelas palavras do enunciado, nenhuma das quatro apresenta uma argumentação tida como "verdade absoluta", isto é, todas representam possíveis relações discursivas.

Segundo Ducrot (2005b), a partir de A e de B (X e Y), podemos construir oito conjuntos de encadeamentos que chamamos de aspectos argumentativos. "Esses oito aspectos, teoricamente possíveis a partir de $\mathrm{A}$ e de $\mathrm{B}$, podem agrupar-se em dois blocos de quatro aspectos cada um ${ }^{6}$ (DUCROT, 2005b, p. 31, tradução nossa). Nesse contexto, construiremos o Bloco Semântico 2, que se configura da seguinte maneira:

I-X DC NEG-Y: Desejar um lugar ideal DC não ser agente transformador

J- X PT Y: Desejar um lugar ideal PT ser agente transformador

K- NEG-X DC Y: Não desejar um lugar ideal DC ser agente transformador

L- NEG-X PT NEG-Y: Não desejar um lugar ideal PT não ser agente transformador

Essas quatro formas de apreender o sentido, portanto, formam o Bloco Semântico 2, que podemos ilustrar pela Figura 4, evidenciando os três tipos de relações existentes entre os aspectos argumentativos.

\footnotetext{
6 "Estos ochos aspectos, teóricamente posibles a partir de A y B, pueden agruparse en dos bloques de cuatro aspectos cada uno" (DUCROT, 2005b, p. 44).
} 
Figura 4 - Bloco Semântico 2

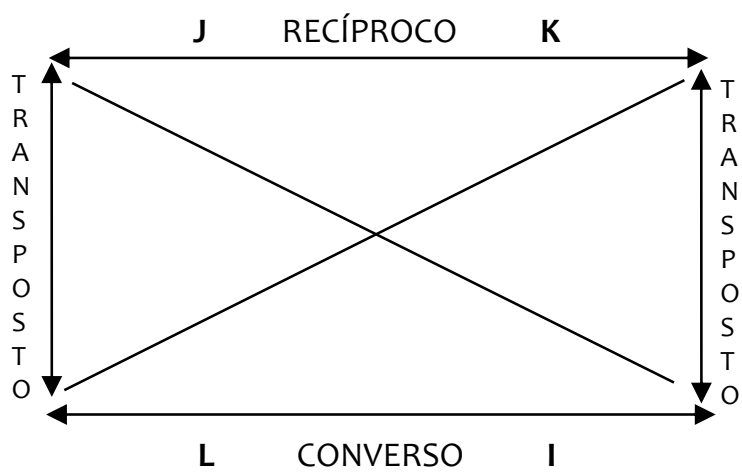

Fonte: elaboração dos autores.

No que diz respeito à análise do anúncio 1, compreendemos que, segundo Ducrot (2005b), os quadrados argumentativos são correspondentes aos blocos semânticos. Nesses aspectos argumentativos apontados no $\mathrm{BS}_{2}$, diferentemente do $\mathrm{BS}_{1}$, percebemos que as possibilidades discursivas distanciam-se do real sentido semântico pretendido pelo locutor. Se observarmos, por exemplo, os aspectos transpostos J e L, temos “Desejar um lugar ideal PT ser agente transformador" e "Não desejar um lugar ideal PT não ser agente transformador”, notamos que ambos são transgressivos. Já os aspectos I e K, "Desejar um lugar ideal DC não ser agente transformador" e "Não desejar um lugar ideal DC ser agente transformador", são predominantemente normativos.

Quando comparamos os blocos semânticos $\left(\mathrm{BS}_{1}\right.$ e $\left.\mathrm{BS}_{2}\right)$ expostos anteriormente, do enunciado “original” do anúncio "Você quer um mundo melhor? Faça a sua parte!", constatamos que o aspecto normativo "Desejar um lugar ideal DC ser agente transformador" seria o aspecto que mais semanticamente faria sentido dentro do universo semântico analisado. Logo, a argumentação do enunciador está inteiramente pautada no aspecto normativo donc (DC/portanto/então), mesmo que esse encadeamento não seja explicitado por um conector.

Se lembrarmos de que o anúncio faz parte da campanha publicitária "For a better world" ("Por um mundo melhor"), verificamos que o encadeamento normativo "querer um mundo melhor DC fazer a sua parte" nos remete a uma ideia de coletividade. O verbo no imperativo - "faça" - convoca, argumentativamente, o alocutário a ter iniciativa, ousadia, a fim de realizar algo importante. Isso desencadeia o sentido de que beber Coca-Cola é fazer a diferença no mundo, ou seja, ser um agente transformador. Assim, na figura 2, é importante considerar que o enunciado dela perpetua o pressuposto basal hodierno de que o mundo está ruim. Ao dizer "Você quer 
um mundo melhor? Faça a sua parte!", diz-se que o mundo não vai bem e que, portanto, precisa do comprometimento das pessoas para transformá-lo.

Neste momento, analisamos o anúncio 2, representado na Figura 5.

Figura 5 - Anúncio publicitário da Coca-Cola de 2016: "Sinta o sabor"

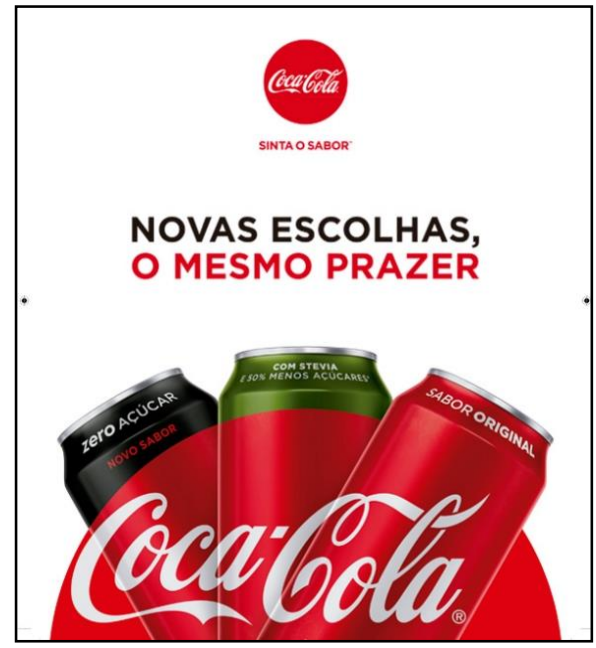

Fonte: Coca-Cola Brasil (2016).

Atentemos para o enunciado: "Novas escolhas, o mesmo prazer". Aqui, construiremos, a partir do encadeamento, a argumentação externa. É importante lembrar que a argumentação externa e a argumentação interna são sempre relativas à entidade ou ao enunciado em análise, nunca externo ou interno em si (LEBLER, 2018).

É possível construir, pela intervenção dos conectores normativos e transgressivos e da negação, oito formas de apreender dois sentidos distintos construindo dois blocos semânticos, cada um deles comportando quatro aspectos argumentativos.

Então, especificamos os quatro aspectos argumentativos, tanto em DC (normativo) como em PT (transgressivo), que são organizados da seguinte forma:
A- X DC Y: Ter novas escolhas DC sentir o mesmo prazer
B-X PT NEG-Y: Ter novas escolhas PT não sentir o mesmo prazer
C- NEG- X DC NEG-Y: Não ter novas escolhas DC não sentir o mesmo prazer
D- NEG-X PT Y: Não ter novas escolhas PT sentir o mesmo prazer

As quatro possibilidades discursivas apresentadas no encadeamento do enunciado não permitem a definição de um desses aspectos para representar o sentido pretendido pelo enunciador, uma vez que o aspecto que melhor condiz com a argumentação apresentada no anúncio é o enunciado "Ter novas escolhas PT sentir o 
mesmo prazer", que apresenta uma argumentação em pourtant, ou seja, transgressiva. Conforme Lebler (2018, p. 33), “A Al é uma ferramenta responsável pela descrição dos sentidos da língua", juntamente com os encadeamentos em donc ou pourtant. Desse modo, vamos nos ater à argumentação interna (Al) do enunciado: “Querer alternar sabores PT obter igual satisfação".

Esse novo encadeamento ( $\mathrm{Al}$ ) compõe o quadrado argumentativo (oito aspectos pertencentes a dois blocos semânticos) dos dois segmentos A e B ( $\mathrm{X}$ e $\mathrm{Y}$ ). Vejamos a possibilidade do primeiro quadrado de encadeamentos semânticos:

E- X DC Y: Querer alternar sabores DC obter igual satisfação

F-X PT NEG- Y: Querer alternar sabores PT não obter igual satisfação

G- NEG-X DC NEG- Y: Não querer alternar sabores DC não obter igual satisfação

H- NEG-X PT Y: Não querer alternar sabores PT obter igual satisfação

A interdependência entre os segmentos de um enunciado resulta na construção de um conteúdo, que pode ser expresso de quatro formas. $\mathrm{O} \mathrm{BS}_{1}$ pode ser ilustrado como consta na Figura 6.

Figura 6 - Bloco Semântico 1

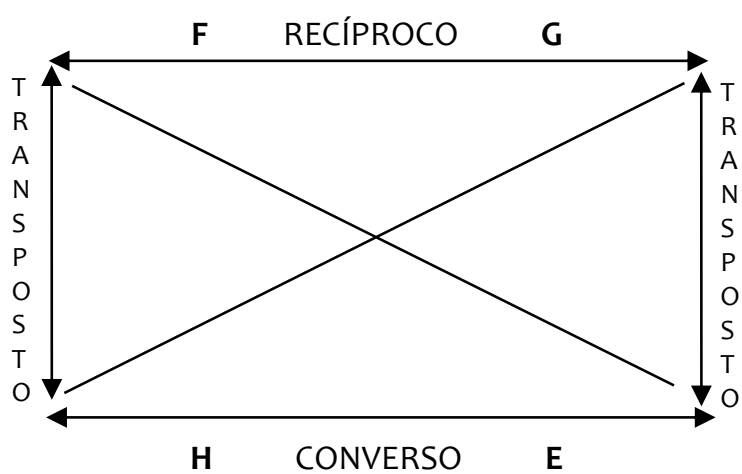

Fonte: elaboração dos autores.

Notamos que todos os aspectos apresentados são possibilidades argumentativas, mas nenhum deles assume o sentido do enunciado, sendo, portanto, necessário construir os outros quatro encadeamentos argumentativos, a fim de estabelecer diferentes sentidos possíveis. Segue o segundo quadrado com os demais encadeamentos possíveis:

I- X DC NEG- Y: Querer alternar sabores DC não obter igual satisfação

J- X PT Y: Querer alternar sabores PT obter igual satisfação

K- NEG- X DC Y: Não querer alternar sabores DC obter igual satisfação

L- NEG-X PT NEG- Y: Não querer alternar sabores PT não obter igual satisfação 
Os quatro modos de apreender o sentido, organizados em um quadrado argumentativo, dispõem-se conforme a Figura 7.

Figura 7 - Bloco Semântico 2

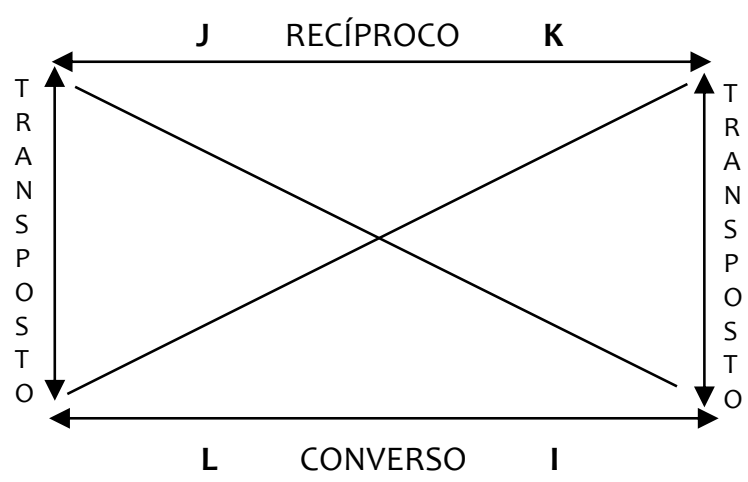

Fonte: elaboração dos autores.

Dessa maneira, comparando os aspectos apresentados nos quadrados argumentativos com o enunciado do texto publicitário "Novas escolhas, o mesmo prazer”, constatamos que, semanticamente, a argumentação aqui utilizada pelo enunciador, diferentemente do primeiro anúncio analisado (Figura 2), está pautada no aspecto transgressivo pourtant, conforme evidenciamos no aspecto: "Querer alternar sabores PT (no entanto/mesmo assim) obter igual satisfação”. Considerando que a campanha publicitária "Taste the feeling" traz o lançamento de novos sabores do refrigerante (zero açúcar e com stévia), o aspecto transgressivo reafirma um discurso que exalta a boa qualidade da bebida. Nesse caso, os consumidores têm total liberdade de realizar novas escolhas porque o prazer do sabor "original” se mantém.

Na sociedade contemporânea há uma intensificação do culto ao corpo, onde os indivíduos têm uma crescente preocupação com a imagem, com a dieta alimentar, a estética e a saúde. Verificamos que as três latas (Figura 5), em gradualidade, apresentam teores semânticos em escala: "zero açúcar" (zero), "com stévia e 50\% menos açúcar" (metade) e "sabor original”, que significa muito açúcar.

As três possibilidades de escolha apresentadas aos interlocutores (consumidores) revelam que ao dizer "novas escolhas" é dizer você poderá reduzir o consumo de açúcar. Em Pressupostos e subentendidos, segundo a teoria da argumentação na língua, Lebler (2016) ressalta que o pressuposto, de acordo com Ducrot, "é parte integrante do sentido dos enunciados, pois não há como enunciar uma frase com pressupostos sem denunciar sua presença; funciona como uma imagem da enunciação, é imposta ao ouvinte” (LEBLER, 2016, p. 313). Nesse contexto, 
percebemos que "novas escolhas" reconstitui e perpetua os pressupostos de que a sociedade consome açúcar e que essa mesma sociedade não quer consumir açúcar. Instaura-se, neste acontecimento (propaganda), a continuação de pressupostos basais atuais do culto pela forma física e a busca por produtos que indicam ser mais saudáveis, o que é reforçado pela expressão zero açúcar.

O uso de enunciados com pressupostos já impõe ao destinatário a imagem do discurso do locutor (LEBLER, 2016). Portanto, conforme os modos de dizer, na perspectiva ducrotiana, enunciar "Novas escolhas, o mesmo prazer", "Sinta o sabor" e "Beba Coca-Cola", na atualidade, significa dizer que o consumidor pode escolher a quantidade de açúcar para beber sua Coca-Cola, sendo que essa escolha, independente de qual seja, não mudará o prazer de beber esse refrigerante.

Diante disso, a análise do corpus desta pesquisa evidenciou a maneira como a argumentação se constrói no discurso dos anúncios publicitários e como ela é marcada pela escolha das palavras por parte do enunciador. Essas escolhas evocam determinados universos de sentido que, quando postos em encadeamentos argumentativos, constroem a argumentação daquele enunciado. Não se trata de convencimento, de persuasão, mas da própria língua colocada em ação pelo locutor.

\section{Considerações finais}

Este estudo está inserido na temática que tem como foco a aplicação de alguns conceitos da Semântica Argumentativa, perspectiva teórica que estuda o sentido construído pelo linguístico sem fazer intervir o extralinguístico. A delimitação do trabalho consistiu em um exercício de aplicação teórico-prática em anúncios publicitários, com base na Teoria dos Blocos Semânticos (TBS), vinculada à Teoria da Argumentação na Língua (TAL), de Oswald Ducrot (1990) e colaboradores.

A questão norteadora deste estudo parte do fato de que os conceitos teóricos da TAL, mais especificamente de sua fase atual, a TBS, podem ser aplicados para descrever o sentido produzido pelos enunciados no discurso dos anúncios publicitários, uma vez que contribuem para a leitura do texto como um conjunto de encadeamentos argumentativos, ligados sob os aspectos normativo (donc = portanto/então) e transgressivo (pourtant = no entanto/mesmo assim).

O objetivo desta pesquisa pôde ser alcançado, tendo em vista que analisamos a construção do sentido dos enunciados pela argumentação que se estabelece exclusivamente por meio da língua no discurso dos anúncios publicitários. A TBS 
aplicada aos anúncios possibilitou depreender o sentido construído pelos encadeamentos das palavras e dos enunciados, uma vez que a significação dos blocos semânticos não resulta da soma dos sentidos das entidades lexicais que os compõem, tomadas isoladamente, mas da interdependência semântica existente entre os segmentos X CON Y.

Verificamos, durante a análise, que o discurso é uma sequência complexa de encadeamentos argumentativos que exprimem argumentações externas e internas das entidades lexicais que os compõem, constituindo, assim, o quadrado argumentativo de um bloco semântico $\left(\mathrm{BS}_{1}, \mathrm{BS}_{2}\right)$. A partir da constituição do bloco semântico, observamos como os enunciados se organizam no interior do texto. Há diferentes formas de apreender o sentido. Com isso, constatamos que os anúncios publicitários estão semanticamente construídos por encadeamentos normativos e transgressivos, mesmo que os encadeamentos não estejam explicitados por um conector na materialidade linguística.

A argumentação do enunciador, no primeiro anúncio analisado, está inteiramente pautada no aspecto normativo (DC/então), conforme o exemplo do aspecto argumentativo “Desejar um lugar ideal DC ser agente transformador”. Já o segundo anúncio apresenta sua argumentação com base no aspecto transgressivo (PT/ mesmo assim), como podemos verificar no enunciado "Novas escolhas, PT (no entanto/mesmo assim) o mesmo prazer”. O sentido construído pelos enunciados revela que os aspectos normativo e transgressivo reafirmam um discurso que exalta a qualidade da empresa Coca-Cola e convoca os interlocutores a fazer a diferença no mundo, enquanto agentes transformadores.

A TBS oferece diversas possibilidades de investigação de diferentes tipos de textos, pois torna possível a compreensão do sentido como um elemento que só existe a partir da língua em uso, ou seja, pelo discurso. Porém, sabemos que o que foi evidenciado nesta pesquisa necessita, ainda, maior investimento de tempo e aprofundamento nos estudos da TAL. De qualquer forma, ressaltamos que a exposição teórica e a análise dos anúncios publicitários trouxeram uma visão mais geral acerca da TBS e de sua relevância acadêmica com vistas à leitura e à interpretação de textos.

A TAL continua sendo estudada e aperfeiçoada por Oswald Ducrot e Marion Carel, porém o foco dos estudos está voltado à perspectiva estruturalista saussuriana de que a argumentação está marcada na língua e não na relação desta com fatos extralinguísticos. A TAL busca no próprio enunciado o seu sentido. 


\section{REFERÊNCIAS}

BARBISAN, Leci Borges; TEIXEIRA, Marlene. Polifonia: origem e evolução do conceito em Oswald Ducrot. Revista Organon, Porto Alegre, v. 16, n. 32/33, p. 161-180, 2002. Disponível em: https://seer.ufrgs.br/organon/article/view/29792. Acesso em: 07. mar. 2021.

BARBISAN, Leci Borges. O conceito de enunciação em Benveniste e Ducrot. In: GIACOMELLI, Karina; PIRES, Vera Lúcia (org.). Émile Benveniste: interfaces enunciação \& discursos. Santa Maria: PPGL Editores, 2006. p. 161-182

BARBISAN, Leci Borges. Semântica Argumentativa. In: JUNIOR, Celso Ferrarezi; BASSO, Renato (org.). Semântica, semânticas: uma introdução. São Paulo: Contexto, 2013. p. 19-30.

CAREL, Marion. Argumentação interna aos enunciados. Letras de Hoje, Porto Alegre, v. 37, n. 3 , p. 27-43, 2002. Disponível em: https://revistaseletronicas.pucrs.br/ojs/index.php/fale/article/view/14222.

CAREL, Marion; DUCROT, Oswald. La semántica argumentativa: una introducción a la teoría de los bloques semánticos. Tradução: María Marta Negroni e Alfredo M. Lescano. Buenos Aires: Colihue, 2005a. p. 11-90.

CAREL, Marion; GOMES, Lauro. A Semântica Argumentativa de nossos dias: questões ligadas às noções de língua, discurso, sentido e enunciação. Signo, Santa Cruz do Sul, v. 44, n. 80, p. 259-275, 2019. DOI http://doi.org/10.17058/signo.v44i80.14023.

COCA-COLA BRASIL. Linha do tempo: conheça a história da Coca-Cola Brasil. 24 maio 2016. Disponível em: https://www.cocacolabrasil.com.br/sobre-a-coca-cola-brasil/a-historia-dacoca-cola-brasil.

DUCROT, Oswald. Esboço de uma teoria polifônica da enunciação. In: DUCROT, Oswald. 0 dizer e o dito. Revisão técnica da tradução: Eduardo Guimarães. Campinas: Pontes, 1987. p. $161-218$.

DUCROT, Oswald. Polifonía y Argumentación: Conferencias del Seminario Teoría de la Argumentación y Análisis del Discurso. Cali: Universidad del Valle, 1990.

DUCROT, Oswald. Os internalizadores. Letras de Hoje, Porto Alegre, v. 37, n. 3, p. 7- 26, 2002. Disponível em: https://revistaseletronicas.pucrs.br/ojs/index.php/fale/article/view/14221

DUCROT, Oswald. Los bloques semánticos y el cuadrado argumentativo. In: CAREL, Marion; DUCROT, Oswald. La Semántica argumentativa: una introducción a la teoría de lós bloques semânticos; edición literaria a cargo de María Marta García Negroni y Alfredo M. Lescano. 1. ed. Buenos Aires: Colihue, 2005b. p. 27-50.

DUCROT, Oswald. Argumentación interna y argumentación externa. Conferencia 3. In: CAREL, Marion; DUCROT, Oswald. La Semántica argumentativa: una introducción a la teoría de lós bloques semânticos; edición literaria a cargo de María Marta García Negroni y Alfredo M. Lescano. 1. ed. Buenos Aires: Colihue, 2005c. p. 51-89.

FLORES, Valdir do Nascimento et al. Dicionário de linguística da enunciação. São Paulo: Contexto, 2009. 
FREITAS, Ernani Cesar de. Semântica argumentativa: a construção do sentido no discurso. Novo Hamburgo, RS: Feevale, 2007.

FUMAGALLI, Rita de Cássia Dias Verdi; FREITAS, Ernani Cesar de. Teoria da Argumentação na Língua e a construção de blocos semânticos: relações de sentido em um texto jornalístico. Entrepalavras, Fortaleza, v. 7, p. 193-214, 2017. Disponível em: http://www.entrepalavras.ufc.br/revista/index.php/Revista/article/view/775. Acesso em: 7 mar.2021.

GOMES, Lauro. Como avaliar a semântica do texto? Uma proposta para a avaliação de redações orientada pela Semântica Argumentativa. São Carlos: Pedro e João Editores, 2017.

GOMES, Lauro. A significação de palavras e o sentido de enunciados e de períodos argumentativos em discursos artísticos escritos: um estudo semântico prospectivo. Tese (Doutorado em Letras) - Programa de Pós-Graduação em Letras da Pontifícia Universidade Católica do Rio Grande do Sul, Porto Alegre, 2020.

LEBLER, Cristiane Dall' Cortivo. Pressupostos e subentendidos segundo a teoria da argumentação na língua. Revista Gragoatá, Rio de Janeiro, v. 21, n. 40, p. 295- 316, 2016. Disponível em: https://periodicos.uff.br/gragoata/article/view/33385. Acesso em: 8 mar. 2021.

LEBLER, Cristiane Dall'Cortivo. Teoria dos Blocos Semânticos: exposição teórica e reflexão. Veredas - Revista de Estudos Linguísticos, Juiz de Fora, v. 22, n. 2, p. 21-37, 2018. Disponível em: https://periodicos.ufjf.br/index.php/veredas/article/view/27935. Acesso em: 7 mar.2021.

PRODANOV, Cleber Cristiano; FREITAS, Ernani Cesar de. Metodologia do trabalho científico: métodos e técnicas da pesquisa e do trabalho acadêmico. Novo Hamburgo: Feevale, 2013.

VOLOTÃO, Amanda. O modo Coca-Cola de ser feliz: ideais de bem viver nas campanhas publicitárias dos anos 1960 e 2000. Dissertação (Mestrado em Comunicação e Cultura) Programa de Pós-Graduação em Comunicação e Cultura da Escola de Comunicação da Universidade Federal do Rio de Janeiro, Rio de Janeiro, 2015. 